\title{
Coarctation repair in neonates and young infants: Is small size or low weight still a risk factor?
}

\author{
Phillip T. Burch, MD, ${ }^{\mathrm{a}}$ Collin G. Cowley, MD, ${ }^{\mathrm{b}}$ Richard Holubkov, PhD, ${ }^{\mathrm{c}}$ Donald Null, MD, ${ }^{\mathrm{d}}$ \\ Linda M. Lambert, MSN, FNP, ${ }^{a}$ Peter C. Kouretas, MD, PhD, ${ }^{a}$ and John A. Hawkins, MD ${ }^{\mathrm{a}}$
}

Objective: Previous reports of neonatal coarctation repair demonstrate a high rate of recurrent arch obstruction in small neonates. This study assesses the effect of patient size on reintervention and survival in neonates and infants undergoing repair of simple aortic coarctation.

Methods: From 1996 to 2006, 167 neonates and infants younger than 90 days with simple coarctation underwent repair. Median patient age was 16 days (range, $1-85$ days). Median patient weight was $3.4 \mathrm{~kg}$ (range, $0.8-6.0 \mathrm{~kg}$ ), with 29 patients weighing less than $2.5 \mathrm{~kg}$. All 167 patients included in the study underwent repair through a left thoracotomy.

\begin{abstract}
Results: There was 1 early death (1/167, 0.6\%). Median follow-up of 4.8 years (range, $0-11.8$ years) demonstrated 2 late deaths unrelated to recurrent coarctation. Eighteen patients underwent intervention for recurrent arch obstruction a median of 0.48 years postoperatively (range, 0.14-9.8 years). All were treated with balloon angioplasty and have required no additional intervention. Actuarial freedom from reintervention was $90 \%$ at 1 year and $89 \%$ at 5 years for infants weighing more than $2.5 \mathrm{~kg}$ and $89 \%$ at 1 year and $86 \%$ at 5 years $(P=$ .31 ) for infants weighing less than $2.5 \mathrm{~kg}$. There was no difference between survival or reintervention for neonates 30 days of age or younger compared with infants 31 to 90 days of age. Use of polypropylene sutures and female sex did correlate with increased reintervention.
\end{abstract}

Conclusions: Low weight does not affect survival or reintervention rates after coarctation repair in neonates and infants less than 3 months of age. Balloon angioplasty is an effective treatment for recurrent obstruction after coarctation repair in infancy. In the current era, timing of the operation should be based on clinical status.

Previous studies have demonstrated that complex cardiac surgery can be performed in low-weight infants with acceptable but increased rates of morbidity and mortality. ${ }^{1}$ In addition, most centers have documented low mortality rates for repair of aortic coarctation. ${ }^{2,3}$ However, conflicting data exist with regard to the effect of low birth weight and small patient size on the incidence of recoarctation. ${ }^{4-7}$ The introduction of prostaglandin $\mathrm{E}_{1}\left(\mathrm{PGE}_{1}\right)$ allows for temporary palliation of aortic coarctation in most cases. In the past, concerns over increased mortality and morbidity in lowbirth-weight infants led some centers to delay surgical intervention, allowing for somatic growth. ${ }^{8}$ This study was designed to evaluate the influence of low weight on recurrent obstruction requiring reintervention and survival in neonates

\footnotetext{
From the Divisions of Cardiothoracic Surgery, ${ }^{\mathrm{a}}$ Pediatric Cardiology, ${ }^{\mathrm{b}}$ Pediatric Critical Care Medicine, ${ }^{\mathrm{c}}$ and Neonatology, ${ }^{\mathrm{d}}$ Primary Children's Medical Center and the University of Utah, Salt Lake City, Utah.

Read at the Thirty-fourth Annual Meeting of The Western Thoracic Surgical Association, Kona, Hawaii, June 25-28, 2008.

Received for publication June 20, 2008; revisions received March 25, 2009; accepted for publication April 27, 2009; available ahead of print July 2, 2009.

Address for reprints: Phillip T. Burch, MD, Divisions of Cardiothoracic Surgery, Primary Children's Medical Center, 100 North Mario Capecchi Dr, Salt Lake City, UT 84113 (E-mail: Phillip.Burch@hsc.utah.edu).

J Thorac Cardiovasc Surg 2009;138:547-52

$0022-5223 / \$ 36.00$

Copyright (c) 2009 by The American Association for Thoracic Surgery

doi:10.1016/j.jtcvs.2009.04.046
}

and infants undergoing repair of simple coarctation of the aorta, as well as to delineate additional factors that might contribute to suboptimal outcomes.

\section{MATERIALS AND METHODS \\ Patients}

The cardiothoracic surgery database at Primary Children's Medical Center was reviewed, collecting data from 1996 to 2006 to identify children less than or equal to 90 days of age who had undergone operations for repair of simple coarctation. The Institutional Review Board at Primary Children's Medical Center and the University of Utah approved this retrospective review. Coarctation was diagnosed based on the presence on echocardiographic analysis of a posterior shelf with flow acceleration and persistence of antegrade flow in the descending aorta during diastole. Simple coarctation was defined as isolated coarctation or coarctation with a hemodynamically insignificant ventricular septal defect (VSD). Additionally, patients with arch hypoplasia that precluded repair through a left thoracotomy approach were excluded as well. A concomitant VSD was deemed to be hemodynamically insignificant if it did not require immediate or subsequent surgical closure. A total of 167 children meeting enrollment criteria were identified. Preoperative weights were available for 161 of these children. Records were reviewed to obtain age, sex, weight, noncardiac anomalies, operative times, complications, mortalities, incidence of reintervention, and additional hemodynamically insignificant cardiac anomalies.

Coexisting cardiac anomalies in these patients are shown in Table 1. Infants weighing less than $2.5 \mathrm{~kg}$ did not have significantly more VSDs $(P=.06)$ or bicuspid aortic valves with a systolic gradient of $30 \mathrm{~mm} \mathrm{Hg}$ or less $(P=.11)$ than infants weighing $2.5 \mathrm{~kg}$ or greater. However, there were significantly more left-sided superior vena cavae among infants weighing less than $2.5 \mathrm{~kg}(P=.02)$. A patent foramen ovale or atrial septal defect 


\section{Abbreviations and Acronyms \\ $\mathrm{PGE}_{1}=$ prostaglandin $\mathrm{E}_{1}$ \\ VSD $=$ ventricular septal defect}

was diagnosed in 138 patients (Table 1). With regard to noncardiac anomalies, 6 patients had renal anomalies, 3 patients had an imperforate anus, and 3 patients had hypospadias. A total of 8 patients had a diagnosis of Turner syndrome (Table 1). A defined syndrome other than Turner syndrome was diagnosed in 5 patients (Noonan, Pierre-Robin, Goldenhar, trichorhinophalangeal, and CHARGE association). Eleven low-weight infants had 23 noncardiac anomalies compared with 18 infants weighing $2.5 \mathrm{~kg}$ or greater who had 24 noncardiac anomalies $(P=.002)$.

Sixty-two percent ( 63 female/104 male) of the patients were male. Estimated gestational age was available for 88 patients, with 27 patients $(31 \%)$ being premature with an estimated gestational age of less than 37 weeks. Median age at the time of the operation was 16 days (range, 1-85 days), with 121 being 30 days of age or less, 25 being 31 to 60 days of age, and 21 being 61 to 90 days of age. Median patient weight was $3.4 \mathrm{~kg}$ (range, $0.8-6.0 \mathrm{~kg}$ ), with 29 weighing less than $2.5 \mathrm{~kg}$ and 132 weighing $2.5 \mathrm{~kg}$ or greater. Of the 29 patients weighing less than $2.5 \mathrm{~kg}$, 9 weighed less than $1.5 \mathrm{~kg}$.

\section{Surgical Technique}

Standard surgical techniques were used, which included a left thoracotomy through the fourth intercostal space and extended end-to-end anastomosis. ${ }^{2}$ All ductal tissue was excised, and the anastomosis was routinely carried proximal to the left subclavian artery onto the transverse arch between the left carotid and subclavian arteries. The arteriotomy was extended more proximally toward the base of the left carotid artery when dictated by the arch anatomy. A running suture of 6-0 or 7-0 polydioxanone sutures or polypropylene sutures of 7-0 or 8-0 caliber was used for the anastomosis, depending on surgeon preference.

\section{Follow-up}

Postoperative follow-up was obtained through direct visits with the patients' pediatric cardiologists. At least 1 year's follow-up was available for 151 of the 164 surviving patients. Patients were screened for recurrent or residual coarctation by means of blood pressure cuff measurement of arm-leg gradients and pulse examinations. Patients with arm-leg gradients of greater than $20 \mathrm{~mm} \mathrm{Hg}$ or discrepant pulse examinations on repeated visits with their cardiologists were further evaluated by using echocardiography. Patients noted to have acceleration of flow across the site of repair, persistence of flow in the descending thoracic aorta during diastole, or evidence of anastomotic narrowing by means of 2-dimensional imaging were referred for cardiac catheterization. The peak arm-leg gradient measured for those patients undergoing intervention ranged from 15 to $68 \mathrm{~mm} \mathrm{Hg}$ (median, $35.5 \mathrm{~mm} \mathrm{Hg}$ ), whereas patients who did not have reintervention had peak arm-leg gradients ranging from 0 to $32 \mathrm{~mm} \mathrm{Hg}$ (median, $7 \mathrm{~mm}$ $\mathrm{Hg}$ ). Outcomes were analyzed for survival and recurrent obstruction requiring reintervention.

\section{Statistical Analysis}

Freedom from reintervention curves were generated by using the Kaplan-Meier method. ${ }^{9}$ Differences in freedom from event (death or reintervention) rates were assessed between patient subgroups by using the log-rank test. Events were also compared between patient subgroups as binary outcomes by using the Pearson $\chi^{2}$ test; in the case of small cell counts, the Fisher's exact test was used. Predictors of events were assessed by using Cox regression; stepwise regression, beginning with variables showing a trend $(P<.1)$ in univariate models, was used to develop a multi-
TABLE 1. Coexisting anomalies

\begin{tabular}{lcc}
\hline & $\begin{array}{c}\text { Weight }<\mathbf{2 . 5} \text { kg } \\
(\mathbf{n}=\mathbf{2 9})\end{array}$ & $\begin{array}{c}\text { Weight } \geq \mathbf{2 . 5} \text { kg } \\
(\mathbf{n}=\mathbf{1 3 2})\end{array}$ \\
\hline Cardiac anomaly & & \\
$\quad$ Ventricular septal defect & $13(45 \%)$ & $35(26.5 \%)$ \\
Atrial septal defect/patent & $23(79 \%)$ & $115(87 \%)$ \\
$\quad$ foramen ovale & & \\
Bicuspid aortic valve & $14(48 \%)$ & $85(64 \%)$ \\
Coronary anomalies & $2(6.9 \%)$ & $1(0.8 \%)$ \\
Left superior vena cava & $6(21 \%)$ & $8(6.1 \%)$ \\
Anatomic arch anomalies & $1(3.4 \%)$ & $4(3 \%)$ \\
$\quad$ RSCA, LSCA, bovine) & & \\
Noncardiac anomaly & & $3(2.3 \%)$ \\
Renal anomalies & $3(10.3 \%)$ & $2(1.5 \%)$ \\
Genitourinary anomalies & $4(13.8 \%)$ & $1(0.8 \%)$ \\
Craniofacial defects & $2(6.9 \%)$ & $1(0.8 \%)$ \\
Spinal defect & $1(3.4 \%)$ & $0(0 \%)$ \\
Skeletal anomalies & $2(6.9 \%)$ & $1(0.8 \%)$ \\
Gastrointestinal defect & $3(10.3 \%)$ & \\
$\quad$ (imperforate anus, & & $8(6.1 \%)$ \\
$\quad$ malrotation, TE fistula) & & $1(0.8 \%)$ \\
Turner syndrome & $0(0 \%)$ & \\
Genetic anomalies & $1(3.4 \%)$ & \\
(excluding Turner syndrome) & & \\
\hline$R S C A$, Right subclavian artery; LSCA, left subclavian artery; TE, tracheoesophageal. \\
\end{tabular}

variable model. All $P$ values are 2 -sided. Mean values of continuous factors were compared between subgroups by using the 2 -sample $t$ test. Normally distributed values are reported as means \pm standard deviations. Medians and ranges for values are included where appropriate.

\section{RESULTS \\ Operative Results}

One hundred sixty-seven patients underwent repair through a left thoracotomy, with a reintervention rate of $10.8 \%$ (18/167). The median clamp time for patients who underwent reintervention was 19 minutes, with a range of 15 to 28 minutes, whereas the median clamp time for children who did not undergo reintervention was 18 minutes, with a range of 10 to 56 minutes $(P=.30)$. Information regarding the type of suture used for repair was available for 166 of the total 167 patients. Of the 125 patients who had the anastomosis performed with polydioxanone sutures, 9 $(7.2 \%)$ had recurrent or residual coarctation, and 8 $(19.5 \%)$ of 41 who underwent repair with polypropylene sutures had recurrence $(P=.04)$. Suture caliber did not significantly affect recurrence $(P=.87)$. The suture material and caliber were based on surgeon preference, with 5 separate surgeons performing the repairs over the course of the study. Surgeon effect assessed by using the Cox proportional hazards model demonstrated no significant difference in recurrence $(P=.43)$. In addition, year of surgical intervention assessed as both a categorical $(P=1.0)$ and continuous $(P=.54)$ variable demonstrated no significant effect on recurrence. 
TABLE 2. Recurrence and mortality based on sex

\begin{tabular}{|c|c|c|c|c|c|c|c|c|}
\hline \multirow[b]{3}{*}{ Sex } & \multicolumn{8}{|c|}{ Weight } \\
\hline & \multicolumn{2}{|c|}{$\geq 2.5 \mathrm{~kg}(\mathrm{n}=132)$} & \multicolumn{2}{|c|}{$<2.5 \mathrm{~kg}(\mathrm{n}=29)$} & \multicolumn{2}{|c|}{$1.5-2.5 \mathrm{~kg}(\mathrm{n}=20)$} & \multicolumn{2}{|c|}{$<1.5 \mathrm{~kg}(\mathrm{n}=9)$} \\
\hline & Male & Female & Male & Female & Male & Female & Male & Female \\
\hline Total no. of patients & 87 & 45 & 14 & 15 & 7 & 13 & 7 & 2 \\
\hline No. of recoarctations & 5 & 8 & 2 & 3 & 0 & 3 & 2 & 0 \\
\hline Early or late mortality & 0 & 2 & 0 & 1 & 0 & 1 & 0 & 0 \\
\hline
\end{tabular}

Of the 88 patients in whom gestational age was ascertained, $6(22.2 \%)$ of 27 premature infants underwent reintervention, whereas $6(9.8 \%)$ of 61 term infants underwent reintervention $(P=.18)$. Information regarding the use of $\mathrm{PGE}_{1}$ was available for 146 patients. Fourteen $(13.3 \%)$ of 105 patients dependent on $\mathrm{PGE}_{1}$ for adequate perfusion underwent reintervention, whereas only 1 (2.4\%) of 41 patients who were not $\mathrm{PGE}_{1}$ dependent underwent reintervention $(P$ $=.07)$. Accurate information regarding ductal patency was present for 162 patients. A patent ductus arteriosus was present in 101 patients, and $10(9.9 \%)$ of these underwent reintervention. Eight $(13.1 \%)$ of 61 patients with a closed ductus arteriosus underwent reintervention $(P=.53)$.

When sex was examined, $6.7 \%$ (7/104) of male patients underwent reintervention, whereas $17.5 \%(11 / 63)$ of female patients underwent reintervention $(P=.03)$. Also, there were no deaths among the male patients $(0 / 104)$, but there were $3(4.8 \%)$ deaths among the female patients $(P=$ .052 , Table 2). Transverse arch diameters recorded as the smallest measured diameter between the left common carotid artery and the left subclavian artery by means of echocardiographic analysis were available for 17 patients who underwent reintervention and 117 patients who did not. The mean transverse arch diameter for patients undergoing reintervention was $3.89 \pm 1.04 \mathrm{~mm}$, whereas the transverse arch of patients not undergoing reintervention was $4.50 \pm$ $1.08 \mathrm{~mm}(P=.03)$. However, when transverse arch diameter was indexed to patient weight, there was no difference between the 2 groups $(P=.87)$.

A total of 18 patients underwent intervention for recurrent arch obstruction at a median of 0.48 years postoperatively (range, 0.14-9.8 years). Actuarial freedom from reintervention was $90 \%$ at 1 year and $89 \%$ at 5 years for infants weighing more than $2.5 \mathrm{~kg}$, whereas for infants weighing less than $2.5 \mathrm{~kg}$, it was $89 \%$ at 1 year and $86 \%$ at 5 years $(P=.31)$. When very low-weight infants $(<1.5 \mathrm{~kg})$ were examined separately, 22\% (2/9) underwent reintervention in comparison with a $9.8 \%(13 / 132)$ rate of reintervention among patients weighing greater than $2.5 \mathrm{~kg}(P=.25)$. With regard to mortality, $1(3.4 \%)$ of 29 children weighing less than $2.5 \mathrm{~kg}$ died, and $2(1.5 \%)$ of 132 children weighing more than 2.5 $\mathrm{kg}$ died $(P=.45)$. Also, 0 of 9 patients weighing less than $1.5 \mathrm{~kg}$ died, which was not significantly different from the mortality in infants weighing greater than $2.5 \mathrm{~kg}(P=1.0$, Table 2). In addition, there was no difference between sur- vival $(P=1.0)$ or need for reintervention $(P=1.0)$ for neonates 30 days or younger compared with infants 31 to 90 days of age (Table 3). The median age at the time of initial coarctation repair for infants undergoing reintervention was 13 days (range, 3-76 days), and for infants not undergoing reintervention, the median age was 16 days (range, $1-85$ days; $P=.45$ ). Table 4 shows risk ratios for variables assessed for association with reintervention through Cox regression. Both patient age at the time of repair $(P=.82)$ and patient weight $(P=.21)$ were assessed as continuous variables, and neither significantly affected the risk for reintervention; categorized versions of these factors also were not significant.

By means of univariate analysis, the suture type used for the anastomosis, sex, and absolute transverse arch diameter all significantly affected the risk of reintervention (Table 4). When multivariate Cox analysis was performed, only the use of polypropylene sutures (risk ratio of 3.31 vs polydioxanone sutures with a 95\% CI of 1.27-8.59) and female sex (risk ratio of 2.77 vs male sex with a $95 \%$ CI of 1.05-7.30) proved to be independent predictors of reintervention. Both the year of surgical intervention $(P=.67)$ and the surgeon $(P=.89)$ performing the operation were included separately in a multivariable model with sex and suture type to determine whether these factors accounted for the observed findings, and neither variable was predictive of recurrence. All patients who underwent reintervention were treated with balloon angioplasty and have undergone no additional intervention to date.

\section{Mortality}

Combined early and late mortality for infants weighing less than $2.5 \mathrm{~kg}$ was $3.4 \%(1 / 29)$, and for infants weighing more than $2.5 \mathrm{~kg}$, combined mortality was $1.5 \%(2 / 132 ; P$ $=.45)$. The 1 early death occurred in a $3.1-\mathrm{kg}$ term infant who presented at 3 days of age with cardiomegaly and acidosis. During preoperative resuscitation, she experienced worsening acidosis and progressive respiratory difficulty caused by increasing ascites, which required percutaneous

TABLE 3. Recurrence and mortality based on age

\begin{tabular}{lrcc}
\hline & \multicolumn{3}{c}{ Age } \\
\cline { 2 - 4 } & $\leq \mathbf{3 0 ~ d}$ & $\mathbf{3 1 - 6 0 ~ d}$ & $\mathbf{6 1 - 9 0 ~ d}$ \\
\hline Total no. of patients & 121 & 25 & 21 \\
No. of recoarctations & 13 & 3 & 2 \\
Early or late mortality & 2 & 1 & 0 \\
\hline
\end{tabular}


TABLE 4. Patient and operative variables assessed for impact on recoarctation

\begin{tabular}{lccc}
\hline \multicolumn{1}{c}{ Variable } & $\begin{array}{c}\text { Univariate } \\
\boldsymbol{P} \text { value }\end{array}$ & $\begin{array}{c}\text { Univariate risk } \\
\text { ratio }(\mathbf{9 5} \% \mathbf{C I})\end{array}$ & Multivariable risk ratio (95\% CI) \\
\hline Crossclamp time (per minute increase) & .40 & $1.05(0.94-1.17)$ & \\
Suture type (polypropylene vs polydioxanone) & .02 & $3.10^{*}(1.19-8.03)$ & $3.31(1.27-8.59)$, multivariable $P=.014$ \\
EGA (<37 wk vs $\geq 37$ wk) & .19 & $2.15(0.69-6.66)$ & \\
PGE ${ }_{1}$ (on vs off) & .10 & $5.61(0.74-42.65)$ & \\
Ductus arteriosus (closed vs open) & .55 & $1.33(0.53-3.38)$ & $2.77(1.05-7.30)$, multivariable $P=.04$ \\
Sex (female vs male) & .03 & $2.88^{*}(1.11-7.43)$ & \\
Absolute transverse arch diameter (per 1-mm increase) & .04 & $0.57 *(0.34-0.96)$ & \\
Age at repair (per 10-d increase) & .82 & $0.97(0.78-1.21)$ & \\
Weight at surgical intervention (per 1-kg increase) & .21 & $0.74(0.46-1.19)$ & \\
\hline$E G$ E E
\end{tabular}

$E G A$, Estimated gestational age. ${ }^{*} P<.05$ for significance of test that risk ratio is different from unity.

drainage. She could not be extubated postoperatively, and subsequent echocardiograms demonstrated suprasystemic pulmonary artery pressures. Despite maximal medical therapy with prostacyclin, nitric oxide, and milrinone, she remained intubated. Cardiac catheterization demonstrated an inferior vena caval thrombus, mild residual gradient (14 $\mathrm{mm} \mathrm{Hg}$ ) across the arch, and no anatomic explanation for the persistent pulmonary hypertension. Given her lack of improvement with maximal therapy, medical support was withdrawn, and the patient died on postoperative day 22 .

Median follow-up of 4.8 years (range, $0-11.8 \mathrm{yrs}$ ) demonstrated 2 late deaths. The first patient was a $2.85-\mathrm{kg}$ term infant who underwent coarctation repair on the sixth day of life. A postoperative echocardiogram demonstrated no residual gradient, and her hospital course was uncomplicated. At 37 days of age, she experienced a cardiac arrest at home and a second arrest at an outlying hospital. On arrival at our institution, she continued to have seizures and worsening renal failure. Given her poor prognosis, support was withdrawn. Autopsy demonstrated subendocardial fibroelastosis of all chambers, as well as subintimal fibrosis of the coronary arteries. Also, there was moderate mitral valve stenosis, moderate left ventricular hypoplasia, and moderate arch hypoplasia, which had not been demonstrated on prior echocardiograms. Despite these findings, the aortic anastomosis was widely patent at autopsy.

The second late death occurred in a 35-week gestational age infant diagnosed with an atrial septal defect, restrictive VSD, bicuspid aortic valve, and coarctation with patent ductus arteriosus. She weighed $2.38 \mathrm{~kg}$ at the time of initial coarctation repair through a left thoracotomy. At 3 months of age, she presented after a cyanotic episode. Echocardiographic analysis demonstrated bilateral pulmonary venous obstruction. Pulmonary venous obstruction was relieved with a sutureless technique but recurred and was deemed inoperable. There was no evidence of recurrent coarctation clinically or at autopsy.

\section{Postoperative Complications}

A total of 21 patients had 27 complications in the postoperative period. Five patients weighing less than $2.5 \mathrm{~kg}$ experienced 5 complications, and 16 patients weighing more than $2.5 \mathrm{~kg}$ experienced 22 complications, which are further delineated in Table 5. There was no significant difference in the incidence of postoperative complications between smaller and larger infants $(P=.46)$. The most common complications were sepsis/infection in 5 patients and chylothorax in 3 patients, 2 of whom required surgical therapy.

\section{DISCUSSION}

Premature and low-weight infants continue to be a source of consternation for congenital heart surgeons. The feasibility of complete repair of congenital heart defects in these small infants has been repeatedly demonstrated. However, operations in premature or low-birth-weight infants are frequently associated with increased morbidity and mortality. ${ }^{1,10-12}$ Previous studies specifically assessing the effect of patient size on outcomes after repair of coarctation have shown mixed results with regard to mortality. Mortality for low-weight infants has been reported to be from $5 \%$ to $15 \%{ }^{4-6,13}$ compared with mortality rates of less than $2 \%$ for repair of isolated coarctation in term infants. ${ }^{2,3,14-16}$ In a study by McElhinney and associates, ${ }^{4}$ low-weight infants had a mortality of $14 \%$, whereas there were no deaths among larger infants. More recently, a review of the Society of Thoracic Surgeons Congenital Heart Database has shown that low weight was associated with increased mortality in

TABLE 5. Postoperative complications

\begin{tabular}{ll}
\hline \multicolumn{1}{c}{ Complications $(\mathbf{n}=\mathbf{2 6})$} & 1 \\
\hline Gastrointestinal bleed & 3 \\
Chylothorax & 1 \\
Medication overdose & 3 \\
Paralyzed vocal cord & 5 \\
Infection/sepsis & 2 \\
Arrhythmia & 1 \\
Spinal cord ischemia & 3 \\
Intraventricular hemorrhage & 2 \\
Tracheal stenosis/cord ulceration & 2 \\
Systemic vein thrombus & 2 \\
Wound complication &
\end{tabular}


infants undergoing isolated coarctation repair. Low-weight infants had 7.1\% mortality, whereas larger infants experienced a mortality of $2.7 \% .{ }^{13}$ In our study mortality for infants weighing less than $2.5 \mathrm{~kg}$ was $3.4 \%(1 / 29)$, and infants weighing more than $2.5 \mathrm{~kg}$ experienced a mortality of $1.5 \%(2 / 132)$. Although our data are similar in magnitude to the Society of Thoracic Surgeons database study, low weight did not confer a worse prognosis with regard to early or late survival after coarctation repair. The overall higher mortality in the older studies is likely explained by the inclusion of infants with complex intracardiac anatomy, as well as the continued evolution of preoperative, intraoperative, and postoperative care. ${ }^{1,8,17}$

Given the overall low mortality associated with repair of isolated coarctation, attention is increasingly focused on postoperative morbidity, namely recurrent or residual coarctation. Little doubt remains that surgical repair is superior to balloon angioplasty of native coarctation in infants. ${ }^{18,19}$ Over the past decade, coarctectomy with extended end-toend anastomosis has become the procedure of choice for coarctation repair in neonates and young infants. ${ }^{20}$ Reported rates of recoarctation typically range from $10 \%$ to $20 \%{ }^{2,14-16}$ Recent studies of low-weight neonates report rates of recoarctation between $7 \%$ and $44 \% .^{4-6}$ Neither McElhinney and associates ${ }^{4}$ nor Sudarshan and colleagues ${ }^{6}$ determined low weight to be a significant factor in recurrent coarctation, which is in agreement with our findings. In our study recoarctation rates for infants weighing more than 2.5 $\mathrm{kg}$ did not differ significantly from those in infants weighing less than $2.5 \mathrm{~kg}$ and ranged from $10 \%$ to $17 \%$. Even in very low-weight infants $(<1.5 \mathrm{~kg})$, in whom the recoarctation rate increased to $22 \%$, there was no significant difference compared with larger infants. This is in contrast to the findings of Bacha and coworkers, ${ }^{5}$ in which they found a $60 \%$ incidence of recoarctation in infants weighing less than $1.5 \mathrm{~kg}$. All but 2 of our recoarctations occurred within the first year after the operation. This is consistent with the findings of other studies. Contrary to the findings of others, however, all of our patients had successful resolution of their recoarctation with balloon dilation. The fact that none of our recoarctations required surgical intervention might be partially explained by our exclusion of patients with Shone's complex, a patient population that is included in some older studies. Another explanation for the success of balloon dilation in our patients is the fact that all of the patients in the study underwent repair through a left thoracotomy. This would indicate that few of our patients had significant arch hypoplasia preoperatively and that the recoarctation was a focal area of stenosis. Although discrete stenoses are easily addressed with balloon dilation, long areas of hypoplasia are best approached surgically.

By means of univariate analysis, female sex, type of suture, and absolute transverse arch diameter had a significant effect on the rate of reintervention for recoarctation in the present study. By using multivariate analysis, only female sex and suture type were independent risk factors for recoarctations that underwent reintervention. Over the time span encompassed by this study, 5 separate surgeons performed coarctation repairs, and the type of suture used was based on surgeon preference. Neither the operating surgeon nor the year of surgical intervention was predictive of recurrence. The finding of higher recurrent stenosis rates in patients repaired with polypropylene sutures compared with absorbable polydiaxanone sutures has been observed both experimentally ${ }^{21}$ and clinically. ${ }^{22}$ McElhinney and associates $^{4}$ demonstrated that arch anatomy is an important variable with a major effect on recurrent stenosis. Although it was statistically significant in our patient population, as determined by means of univariate analysis, small absolute transverse arch diameter was not an independent predictor of reintervention in the current study. The finding of female sex negatively affecting reintervention rates cannot be readily explained. There was only 1 patient among the 11 female patients who underwent reintervention that carried a diagnosis of Turner syndrome. To our knowledge, the negative effect of female sex on reintervention has not been reported in other series. ${ }^{2,4,14}$

This study is unique in that it contains a comparatively large number of low-weight infants. In addition, low-weight infants are compared with normal-weight infants undergoing repair over the same period of time within the same institution. Furthermore, the technique of repair was uniform and did not change over the time course of the study. Finally, although the patient cohorts of other studies have been rather heterogeneous with regard to cardiac anatomy, we set strict exclusion criteria to ensure the patients in this study were being treated for isolated coarctation and the hemodynamic effects of additional complex intracardiac anatomy were ameliorated.

This study demonstrates that low weight, specifically weight less than $2.5 \mathrm{~kg}$, does not negatively affect survival or recurrent arch obstruction after repair of isolated aortic coarctation in neonates and infants less than 3 months of age. Balloon angioplasty is an effective treatment for recurrent obstruction in this select group of patients. Delay of surgical intervention is unlikely to result in somatic growth given that no patient in this study transitioned from a birth weight of less than $2.5 \mathrm{~kg}$ to a weight at the time of surgical intervention of more than $2.5 \mathrm{~kg}$. These results indicate that delayed intervention to achieve somatic growth is not indicated in the current era and that operations should be undertaken when the clinical situation indicates, even in small neonates and infants.

\section{References}

1. Reddy VM, McElhinney DB, Sagrado T, Parry AJ, Teitel DF, Hanley FL. Results of 102 cases of complete repair of congenital heart defects in patients weighing 700 to 2500 grams. J Thorac Cardiovasc Surg. 1999;117:324-31. 
2. Conte S, Lacour-Gayet F, Serraf A, Sousa-Uva M, Bruniaux J, Touchot A, et al. Surgical management of neonatal coarctation. J Thorac Cardiovasc Surg. 1995; 109:663-75.

3. Knott-Craig CJ, Elkins RC, Ward KE, Overholt ED, Razook JD, McCue CA, et al. Neonatal coarctation repair: influence of technique on late results. Circulation. 1993;88(suppl):II198-204.

4. McElhinney DB, Yang SG, Hogarty AN, Rychik J, Gleason MM, Zachary CH, et al. Recurrent arch obstruction after repair of isolated coarctation of the aorta in neonates and young infants; is low weight a risk factor? J Thorac Cardiovasc Surg. 2001;122:883-90.

5. Bacha EA, Almodovar M, Wessel DL, Zurakowski D, Mayer JE, Jonas RA, et al Surgery for coarctation of the aorta in infants weighing less than $2 \mathrm{~kg}$. Ann Thorac Surg. 2001;71:1260-4

6. Sudarshan CD, Cochrane AD, Jun ZH, Soto R, Brizard CP. Repair of coarctation of the aorta in infants weighing less than 2 kilograms. Ann Thorac Surg. 2006;82: 158-63.

7. Kecskes Z, Cartwright DW. Poor outcome of very low birthweight babies with serious congenital heart disease. Arch Dis Child Fetal Neonatal Ed. 2002;87:F31-3.

8. Chang AC, Hanley FL, Lock JE, Castaneda AR, Wessel DL. Management and outcome of low birth weight neonates with congenital heart disease. $J$ Pediatr. 1994;124:461-6.

9. Kaplan EL, Meier P. Non-parametric estimation from incomplete observations. J Am Stat Soc. 1958;53:457-81.

10. Reddy VM, Hanley FL. Cardiac surgery in infants with very low birth weight. Semin Pediatr Surg. 2000;9:91-5.

11. Rossi AF, Sciden HS, Sadeghi AM, Nguyen KH, Quintana CS, Gross RP, et al. The outcome of cardiac operations in infants weighing two kilograms or less. J Thorac Cardiovasc Surg. 1998;116:28-35.

12. Oppido G, Napoleone CP, Formigari R, Gabbieri D, Pacini D, Frascaroli G, et al. Outcome of cardiac surgery in low birth weight and premature infants. Eur J Cardiothorac Surg. 2004;26:44-53.
13. Curzon CL, Milford-Beland S, Li JS, O’Brien SM, Jacobs JP, Jacobs ML, et al. Cardiac surgery in infants with low birth weight is associated with increased mortality: analysis of the society of thoracic surgeons congenital heart database. J Thorac Cardiovasc Surg. 2008;135:546-51.

14. Quaegebeur JM, Jonas RA, Weinberg AD, Blackstone EH, Kirklin JW. Outcomes in seriously ill neonates with coarctation of the aorta: a multiinstitutional study. J Thorac Cardiovasc Surg. 1994;108:841-54.

15. Zehr KJ, Gillinov AM, Redmond JM, Greene PS, Kan JS, Gardner TJ, et al. Repair of coarctation of the aorta in neonates and infants: a thirty-year experience. Ann Thorac Surg. 1995;59:33-41.

16. Fenchel G, Steil E, Seybold-Epting W, Seboldt H, Apitz J, Hoffmeister HE. Repair of symptomatic aortic coarctation in the first three months of life: early and late results after resection and end-to-end anastomosis and subclavian flap angioplasty. J Cardiovasc Surg. 1988;29:257-63.

17. Wernovsky G, Rubenstein SD, Spray TL. Cardiac surgery in the low birth weight neonate: new approaches. Clin Perinatol. 2001;28:249-64.

18. Fiore AC, Fischer LK, Schwartz T, Jureidini S, Balfour I, Carpenter D, et al. Comparison of angioplasty and surgery for neonatal aortic coarctation. Ann Thorac Surg. 2005;80:1659-65.

19. Rao PS, Galal O, Smith PA, Wilson AD. Five- to nine-year follow-up results of balloon angioplasty of native aortic coarctation in infants and children. $J$ Am Coll Cardiol. 1996;27:462-70.

20. Backer CL, Mavoroudis C, Zias EA, Amin Z, Weigel TJ. Repair of coarctation with resection and extended end-to-end anastomosis. Ann Thorac Surg. 1998; 66:1365-71.

21. Chiu IS, Hung CR, Chao SF, Huang SH, How SW. Growth of the aortic anastomosis in pigs: comparison of continuous absorbable suture with nonabsorbable suture. J Thorac Cardiovasc Surg. 1988;95:112-8.

22. Hawkins JA, Minich LL, Tani LY, Ruttenberg HD, Sturtevant JE, McGough EC. Absorbable polydioxanone suture and results in total anomalous pulmonary venous connection. Ann Thorac Surg. 1995;60:55-9. 